\title{
Creating Spaces and Enabling Transitions for Engagement in SoTL: Can Policy Provide a Framework for Action?
}

\section{Rejoice Nsibande}

\begin{abstract}
Much has been written on the conceptualisation of the scholarship of teaching and learning (SoTL), and on the approaches and methods used by scholars across the globe. A major challenge is how SoTL can be moved from being an add-on option for academic staff, to a culture embedded in the way higher education institutions engage with teaching and learning. This paper reflects on an institutional policy on the evaluation of teaching as a means to create spaces and enable transitions for academics' engagement in SoTL. Elements of the policy aimed at encouraging SoTL and their implications for the anticipated change are discussed. The paper argues that the practices foregrounded in the policy statements create spaces to support academics' transitions to engage in SoTL. However, for this to happen, the paper suggests that a clear strategy is needed to support change at all levels. This strategy should provide support and guidance on the uptake of SoTL at the individual, faculty, and institutional level.
\end{abstract}

Keywords: evaluation of teaching; policy on the evaluation of teaching; scholarship of teaching and learning; change theory

\section{Introduction}

The scholarship of teaching and learning (SoTL) is gaining prominence in higher education, which has led to the generation of an extensive body of literature in response to the demand for guidance on 'what it is' and how it is 
different from or similar to other scholarship such as research. Some considerations when describing SoTL are engagement with knowledge on teaching and learning in order to develop specific knowledge in teaching in the discipline, engagement in deep and systematic reflection as a form of inquiry and efforts to share the knowledge with peers so that it can be scrutinised (Shulman 1999; Hutchings \& Shulman 1999; Kreber \& Cranton 2000; Kreber 2007). The work done focuses on the purpose and significance of SoTL (Hutchings \& Shulman 1999) with the emphasis on student learning. Examples of the work conducted by SoTL scholars are provided showing the methods and approaches used and highlighting the importance of context in understanding SoTL (Hutchings 2000; Booth \& Woollacott 2015). Despite all the scholarly clarifications and definitions of SoTL, it remains a fluid and challenging concept (Boshier 2009; Manarin \& Abrahamson 2016) that influences trends on uptake in institutions.

As is the case in other countries, scholars in South Africa (SA) are concerned with clarifying what SoTL is and its focus (Leibowitz 2010; Booth \& Woollacott 2015), particularly in the SA context (Leibowitz \& Bozalek 2015). Leibowitz and Bozalek (2015) highlight the influence of the apartheid legacy and argue that it is for this reason that student learning should be placed at the centre of the discussion, which should be informed by a social justice agenda. A publication edited by Booth and Woollacott (2015) provides examples of the kind of SoTL work that scholars have done in different contexts (cf. Pitso 2015; Booth 2015; Cameroon 2015; Osman \& Booth 2015). Another critical aspect of SoTL is its role in supporting the professional development of academics as teachers in higher education (Leibowitz 2010; Cameroon 2015).

A critical area that needs attention is how SoTL - as an imperative in the professional development of academics as teachers and in the transformation of teaching and learning - can be supported to grow institutionally. There are limited examples of how engagement in SoTL can be embedded in institutional culture by building on existing structures. This will help create a critical mass of scholars so that the 'transformative potential' of SoTL (Booth \&Woollacott 2015) can be realised. Ways have to be found to enhance the uptake of SoTL by moving from engagement by interested individuals to a movement across institutions (Moutlana \& Moloi 2014; Vithal 2016). Moutlana and Moloi (2014) argue that a system of recognition and rewards can embed SoTL in an institution in the same way that the culture of 
research has been established. Vithal (2016) concurs and adds that because SoTL cannot be imposed on scholars, an 'organic approach' is needed that takes shape over time and that is 'inclusive and multidimensional' to drive the uptake of SoTL across the institution. It is here that this paper seeks to make a contribution by analysing an institutional policy that calls for the use evaluations of teaching to reflect on areas of teaching and learning requiring further investigation as part of SoTL.

The University of the Witwatersrand (Wits University), through its policy on the evaluation of teaching, links the conducting of evaluations with the possibility of engaging in SoTL (undated). Wits policies have a five-year cycle after which they are reviewed. In the current evaluation of teaching policy, evaluations are seen as a way of triggering thinking about areas of inquiry that could be investigated as part of SoTL. Although I have not conducted specific research on the topic, I have observed that evaluation results are not used optimally to identify teaching and learning areas that need further investigation and or improvement as required by the policy. It should be noted that this is not to suggest that no scholars are engaging in SoTL at Wits - the issue is the level of uptake. This paper reflects on the extent to which the policy enables meaningful engagement in SoTL. Drawing on Vithal's (2016) idea of growing SoTL organically, the purpose of the paper is not to 'sell' policy as a way to mandate engagement in SoTL. It argues merely that when policy is used to create space for the development of SoTL, underpinning policy principles should be adopted to develop a strategy to support the achievement of SoTL goals. This strategy should focus on all levels of the system for effective change (individual, faculty, and institution). Valters (2015: 11) advises that 'social contexts and processes are always in flux, with emergent issues, unforeseen risks and surprises arising throughout'. This speaks to the 'messiness' of social contexts and social change - changes do not enter neatly into social contexts as they often compete with other existing demands.

\section{SoTL a Work in Progress: Purpose, Definition, Approaches, and Practices}

As SoTL gained prominence as one of the scholarships in higher education, scholars focused on clarifying what it is, what it is about, and how it is different from other scholarships (Shulman 1999; Hutchings \& Shulman 1999; 
Hutchings 2000; Kreber \& Cranton 2000; Kreber 2007). One way SoTL can be defined is as follows:

A scholarship of teaching is not synonymous with excellent teaching. It requires a kind of 'going meta', in which faculty frame and systematically investigate questions related to student learning - the conditions under which it occurs, what it looks like, how to deepen it, and so forth - and do so with an eye not only to improving their own classroom but to advance practice beyond it (Hutchings \& Shulman 1999: 13).

SoTL goes beyond what is normally expected of good teaching as it involves inquiry and reflective practice in order to develop knowledge on student learning. Hutchings concurs with the above definition and suggests also that SoTL can be viewed in a broad sense in the following way:

... also, the work that scholarly teachers are doing when they make inquiries into their classroom practice, document their work, and make it available to peers in relatively informal settings (Hutchings 2000: 9).

Hutchings maintains that inquiry is at the heart of the work of teachers in higher education and that such inquiry often begins with pragmatic questions that can be pitched at different levels. It starts on the first level with questions on effectiveness (what works) and, on the second level, it is about describing what the teaching activity looks like. The two levels are about descriptions, and what follows are questions on what is possible in a particular teaching context with the possibility of theory building as the final level. Hutchings' (2000) taxonomy can be linked to Booth and Woollacott's (2015) discussion of a model of becoming a scholarly teacher. Quoting from Ashwin and Trigwell's 2004 publication, Booth and Woollacott (2015) highlight that in this model, the first level focuses on investigating teaching practices in order to improve them, a process that is inward looking. The second level is about investigating teaching practices in order to generate knowledge about teaching and learning that can be shared with peers. The third level engages peers through publications in appropriate journals with the aim of producing knowledge that addresses teaching and learning issues beyond the individual's teaching context. It is important to note that not all academic staff are expected to reach Level 3 - 
what is crucial, however, is investigating teaching practice with peers in order to improve student learning and professional development (Leibowitz 2010).

Although there are variations in the way SoTL is conceptualised, especially on how to share the knowledge developed (Boshier 2009; Stefani 2011), common elements are evident in the literature. Scholars agree that SoTL is an inquiry (posing questions and conducting investigations) that is focused on developing both knowledge of teaching in the discipline and knowledge of student learning. The outcomes of the investigations are then shared openly with colleagues in the field and allow other people to build on these outcomes as well. Linked to this is the understanding that responding to questions on student learning requires collaboration among peers at different levels (between disciplines and across disciplines and institutions) (Hutchings \& Shulman 1999; Booth \& Woollacott 2015). Hutchings and Shulman (1999) argue that developing knowledge on teaching and student learning in higher education is not a project for an individual but for scholars working together. Leibowitz (2010), too, argues that for SoTL to demonstrate critical engagement, it should reflect certain features that are at the core of the process. One feature is collaboration (working with other people such as peers and students), which requires openness as professionals systematically engage with their teaching practice in order to improve student learning. A second feature is broadening engagement across disciplines in an attempt to find new ways to solve teaching and learning problems (see also Vithal 2016). Leibowitz (2010) maintains that the deep reflection process should interrogate the assumptions informing practices in disciplines as these often shape teaching processes and views on knowledge and its production. Scholars collaborating on SoTL can be seen as learning communities that provide a setting in which peers support each other in the process by sharing knowledge, methods and dispositions. Osman and Booth (2015: 163) succinctly describe learning in the communities this way:

In this process of sharing and critiquing practical knowledge there is an opportunity for teachers to produce professional knowledge about their fields and disciplines.

This collaborative process further motivates participation and improve craft in a way that could contribute positively on the growth of SoTL over time.

Another critical issue dealt with in the literature concerns the focus and purpose of SoTL, especially when responding to the needs of particular 
contexts. In addition to generating knowledge on student learning in different disciplines, SoTL has to focus on broader issues in higher education (Kreber 2007). Concurring with this view, Stefani (2011) argues that the nature and focus of SoTL should be guided by an appreciation of what the purpose of a university is in the $21^{\text {st }}$ century beyond the basic acquisition of subject content. In the SA context, SoTL, when conducted properly, can be a means of addressing deeper historical issues in higher education (Leibowitz 2010) as more students from different backgrounds access higher education. Vithal (2016: 3) says the following in this regard:

Higher education institutions in South Africa have undergone substantial changes in the two decades since the advent of democracy to redress the past injustices and inequalities ... As student participation rates have increased, another strong national concern has risen for improving quality in Teaching \& Learning.

This means there is a need for a different way of thinking about teaching and learning, a way that takes into account the context of the students participating in higher education. Of importance is how the process is enabling all students to participate equally and have a fair chance to succeed with attributes that will not only advance them in the work place but also prepare them for their roles as citizens in a democratic society (Council on Higher Education 2015).

Leibowitz (2010) and Leibowitz and Bozalek (2015) state that in order to address the SA teaching and learning context effectively, engagement in SoTL work should be informed by social justice principles. In SA, student success is a major problem (Leibowitz 2010; Leibowitz \& Bozalek 2015; CHE 2015; Vithal 2016), and SoTL could be a way to understand and deal with some of the contributing factors. There is an urgent need to understand the critical questions that should be posed for the enquiry and the methods that should be used to respond to contextual issues. As to the nature of the questions, Leibowitz (2010) argues that SoTL should ask value-based questions on teaching processes and their meaningfulness to student learning, questions on issues that are critical to higher education. and questions on critical issues that are significant to society such as meeting the learning needs of all students so as to improve success rates. A variety of different questions can inform SoTL activities but at the heart of the work should be student learning (Hutchings \& Shulman 1999). This emphasises the point that SoTL goes beyond teaching ef- 
fectiveness. Its main objective is to address challenges in the teaching and learning context so that student success can be enhanced.

It can thus be claimed that SoTL supports the professional growth of teaching professionals in a way that serves students and institutions thereby advancing teaching and learning in higher education. Lee Shulman in his keynote address at the UKZN's $10^{\text {th }}$ Teaching and Learning conference held in Durban (September 2016) said that we engage in SoTL because of the professional, intellectual, and moral aspects of the work we do in higher education. This suggests that engagement in SoTL should contribute to the broader issues that impact student learning. Vithal (2016: 4) clarifies this point as follows:

... SoTL that takes student learning needs as a focus from the outset, producing knowledge which is oriented towards solving specific problems by academics from a number of disciplines and favouring dissemination through practice as well as publication.

SoTL thus goes beyond legitimising or providing justification (Hojlund 2014) for personal decisions on teaching practices in its endeavour to identify ways of engaging in teaching and learning that enhance students' learning experiences.

The fluid nature of its conceptualisation sometimes makes it difficult to grasp what SoTL actually is and how it is different from other ways of engaging, especially if SoTL work is to be acknowledged and rewarded (Boshier 2009; Stefani 2011). According to Boshier (2009), few staff members and institutions fully understand the nature of SoTL and its related practices (methods and nature of the knowledge produced) thus leading to major difficulties in rewarding those involved. This has dissuaded a number of people from learning more about SoTL or participating in SoTL work. In Stefani's (2011: 11) view, the difficulties are exacerbated when SoTL is used as a 'mantra to give teaching and learning greater symbolic capital as research with very little understanding of its key principles and implications thereof for practice'. In addition to the conceptualisation challenges, there are also problems with the methods used, including the nature of the questions posed for SoTL work.

Research into SoTL has revealed that the questions we ask, or fail to 
ask, as researchers influence the shape and form of SoTL output (Manarin \& Abrahamson 2016: 1).

The questions framed for the inquiry and the methods of engagement shape what is seen as SoTL and the nature of knowledge produced (Boshier 2009). Although the variations are indicative of the way SoTL responds to contextual needs (Hutchings 2000), this has led to the somewhat troublesome nature of the knowledge of SoTL.

Manarin and Abrahamson $(2016 ; 1)$, in their work on the subject, confirm that in the most cases the nature SoTL knowledge is experienced as 'troublesome'. The authors argue that the attempts to explain SoTL have not helped as the challenge relates to the knowledge and methods of inquiry that are foreign to 'normal' ways of working in disciplines - SoTL thus requires a 'new epistemology'. For instance, it requires knowledge of reflective practice, action research, openness to peer review, and understanding of professional development - and all of these are new ways of engaging. The troublesome nature of SoTL is experienced also on another level as acquiring these ways of engaging has implications for identify shift and formation - discipline experts are thus becoming scholars of teaching and learning. This indicates the need for support and also acknowledgement of the factors that are at play in the particular contexts where practitioners are engaged in SoTL. Manarin and Abrahamson (2016: 1) agree that:

SoTL has the potential to become a vehicle for transition, inquiry, and growth, working between disciplines and sharing common practice.

The challenges related to knowledge of SoTL serve as a caution for what is critical in supporting engagement but do not imply that institutions should slow down adoption of SoTL. Due to the 'transformative potential' of SoTL, alluded to by Booth and Woollacott (2015), in dealing with issues of teaching and learning, there is a need to forge ahead. However, relevant support is needed to help scholars. Development of the required competencies (relevant knowledge, skills, and values), rewards, and recognition, as well as resources, will not only motivate take-up of SoTL but will also help it grow as part of institutional culture (Vithal 2016).

The emphasis throughout the literature review is the importance of adopting a scholarly approach to teaching as a step beyond achieving the good 
teaching expected of everyone. This section of the paper highlighted the conceptualisation of SoTL and the need for institutions to plan carefully for the support required for the uptake of SoTL.

\section{Evaluation of Teaching and Engagement in SoTL: Policy Intentions}

The policy under discussion is being reviewed according to university guidelines for policy reviews. The policy states that all academics should elicit feedback on their practice through peer reviews, student feedback, and selfreflection. Such feedback should be used to identify areas that need further scrutiny in SoTL work. In the guidelines section, the policy explicitly links evaluations of teaching with SoTL in the following ways:

Evaluation of teaching enables lecturers to become reflective practitioners through a process of receiving feedback about, and observing their own practice and their assumptions about teaching and learning. Rigorous self-reflection enables lecturers to identify areas for improvement and strengths which can be built upon, and set professional development goals for themselves (University of the Witwatersrand n.d. 2).

The evaluation of teaching should form part of reflective practice. In this way, it can enhance the scholarship of teaching by promoting the critique of practice that is often facilitated by conversations about teaching among peers and by reference to educational theory and literature (ibid: 2).

It is important to state clearly that the policy does not suggest that evaluations are part of SoTL. However, it does suggest that evaluation feedback should be used to identify and pose questions crucial to SoTL enquiry. These questions could be at the level of asking 'what is effective' in teaching practice (Hutchings 2000) and how student learning is supported. The policy directives are in line with the broad conceptualisation of SoTL provided by Hutchings (2000) and Hutchings and Shulman (1999). SoTL calls for systematic enquiry into practice; it involves thinking about courses, facilitation of learning, and trying new ways of teaching. This process is guided by questions about student 
learning informed by evaluation feedback followed by commitment and openness to emerging issues and further sharing with peers. These are critical aspects of SoTL. The process is focused on value-based questions (Leibowitz 2010) that promote understanding of the conditions that are conducive to student learning in disciplines and across institutions. For example, careful thought and deep reflection are needed on which students are benefiting from current teaching practices and which students are not benefiting and the reasons for this.

The policy calls for reflective practice that provides an opportunity for making sense of practice as academics take 'a learning approach to their teaching' (Osman \& Booth 2015: 166). This learning approach is about 'perspective making and perspective taking' guided by literature and conversations with peers. It is an opportunity for more advanced ways of reflecting on practice that can lead to profound responses to the teaching and learning needs in particular contexts. In this context, SoTL is seen as an opportunity for academics to develop in-depth understanding of their teaching practice by asking questions on how learning is supported, by finding evidence for this, and by finding best ways to improve learning. The inquiries and related findings are shared with peers so that they can be scrutinised and used to redirect practice. Reflective practice is a critical component of the higher education practice; however, it cannot be assumed that everyone has the competence to engage in deep reflection that will support the required engagement in SoTL. It is not that the institution through the policy believes that all academic staff will engage in SoTL; it is about creating the opportunity to see teaching as an intellectual project to support student learning and the professional development of academics.

The policy connects the purpose of evaluation to professional development (Leibowitz 2010) by using feedback to reflect and deepen knowledge on how to teach in different disciplines. See the following extract in this regard:

... to foster among new academic staff and continuing staff a commitment first to excellence in classroom instruction and management and second to service and professional growth and development (University of the Witwatersrand. Undated: 2).

However, this intention is in contrast to an element of 'accountability' implied 
in some of the policy statements such as the following:

School, faculty and university management will have at their disposal valid documentation to assist them in making sound and objective decisions with regard to probation, promotion and performance appraisal ... the university will better be able to reward satisfactory, distinguished, and excellent achievement among lecturers (ibid: 1).

Accountability influences the approaches and methods seen as appropriate for conducting evaluations as well as for the use of the feedback. Evaluations of accountability are aimed at demonstrating the effectiveness of teaching practices as part of quality assurance processes. Accountability is welcomed in higher education; however, in practice, it can override what would have been spaces for enhancing the quality of teaching and learning. This impacts on collecting feedback that supports professional development and the improvement of student learning as the emphasis is more on survey scores than qualitative feedback. The policy guidelines stipulate that:

Schools need to ensure that the source of feedback, and the methodology chosen are sensitive to their particular teaching context, and are appropriately customised (University of the Witwatersrand. Undated: 4).

However, this is overtaken by processes that are meant to maximise objectivity so that rewards can be granted to those who deserve. Linking evaluations with rewards undermines a culture of collegiality and strengthens isolation and competition. Even though the policy 'commits to creating an environment in which it is 'safe' for lecturers to observe and reflect upon their practice openly and honestly' (University of the Witwatersrand. Undated: 2), using evaluations for accountability purposes promotes 'survival' leading to a complex and high stakes process. This high-stake environment shapes the extent to which evaluations are used to inform SoTL work as intended by the policy. In addition, evaluations that influence questions critical to engagement in SoTL require the use of appropriate methods to elicit useful feedback. Surveys that generate scores to indicate student satisfaction do not produce data that can promote endeavours to think about SoTL inquiries constructively.

The policy preamble indicates that the individual academic is respon- 
sible for conducting evaluations of teaching and using the feedback to support deep reflections that can lead to thinking about teaching and learning areas that need further investigation. The following policy statement assumes all academics are motivated to engage with the process in an intellectual and scholarly way:

This commitment to learning could be pursued deliberately by academics that, as professional educators, take control of their teaching practice and seek to research and improve it, supported by communities of good teaching practice (ibid: 1).

Implied here is that academics should find ways to address all factors that can impact on student learning, with the assumption that they are competent to do this effectively. These factors could include teaching approaches, conceptions of how students learn, and curriculum issues. The conducting of evaluations and using them to identify areas of teaching that need further research is the responsibility of academics as part of their ongoing professional practice. This suggested way of engaging should be appreciated and interrogated within the existing evaluation culture in the particular institution, focusing specifically on the extent to which this culture supports policy goals (Trowler 2015; Valters 2015).

The changes discussed above are at the level of the individual, faculty (and/or schools), and institution. The policy requires academics to use evaluation feedback to engage in deep reflection on their teaching practice not only for their professional development but also for development of knowledge that can transform teaching and learning. The policy assumes that academics have the motivation and competence to engage in systematic inquiries of practice in collaboration with colleagues who can also play the role of critical friends in the process (Hutchings \& Shulman 1999; Booth \& Woollacott 2015). Both the faculty and institutional processes are expected to create safe spaces for these changes by encouraging engagement and also rewarding those who do engage. The changes discussed here need to be looked at in light of the 'messiness' of social change so that strategic support can be offered. The changes expected to facilitate engagement in SoTL need to be nurtured and supported over time.

The following section draws on ideas from change theory and social practice theory aimed at looking critically at the elements of change implied in 
the policy and the implications for practice (developing strategies to support the achievement of policy intentions). Trowler (2015) points out that underpinning any theory of change is the need to understand social reality. It is then important to identify and think carefully about what is seen as an effective way to support envisaged change. This section discusses the changes envisaged by the policy, highlights some of the challenges that impact on the realisation of goals, and suggests what should be considered when developing a strategy to support change.

\section{Developing a Strategy to Support Policy Intentions}

In principle, the policy creates spaces to support and encourage engagement in SoTL. However, the implied changes require a clear strategy that links policy principles to explicit action plans on how to drive SoTL in an institution. Drawing on Fullan (2006: 4), the discussion should:

Include harder questions - 'under what conditions will continuous improvement happen?' and, correspondingly, 'How do we change cultures?'

Planning for change requires thought on the conditions necessary for nurturing continuous deep change that would improve engagement in SoTL at the level of individual agency and institutional culture. In order to support the intended policy changes discussed in the previous section, it is useful to draw on change theory (Elmore 2004; Fullan, 2006; Funnell \& Rogers 2011; Trowler 2015; Valters 2015) and social practice theory (Reckwitz 2002) in order to interrogate the implications for practice. Change theory holds that identifying the expected changes and clarifying how they will happen needs to be scrutinised in order to plan strategies that over time will support the targeted changes in practice. Clarity on the expected changes can facilitate communication with stakeholders and can also inform strategies to support engagement. Of importance is that the strategies should consider issues at the different levels at which the system should be nudged to ensure uptake of SoTL over time.

The changes expected at the level of the individual (reflective practice, knowledge of education theories on student learning, and framing enquiries for SoTL based on evaluation feedback and engagement with peers) require profound change and not just exposure to knowledge. This is a new way of 
engaging that calls for changes in deeply ingrained assumptions about student learning in disciplines and in approaches and methods of working (conducting evaluations and engagement in SoTL). The challenge is to understand the nature of SoTL, its knowledge base, and how the expected changes are likely to occur in a given context.

The conducting of evaluations and engagement in SoTL should be seen as social practices (Saunders 2012), which have three important elements (Reckwitz 2002); meanings (conceptualisation), know how (skills), and resources (tools and spaces). All the elements need to be in place for the evaluations to feed into SoTL. The importance of academics' understanding of evaluations and their purpose, especially when linked to SoTL, their skills in conducting evaluations, and their capacity to interpret feedback as well as use it accordingly, cannot be overstated. Developing a conceptual understanding of SoTL and acquiring the competence in the methods required to engage as well as the resources to do the work are equally critical. The competencies required to engage in SoTL, such as reflective practice (criticality and reflexivity), knowledge of educational theories, and relevant methods are foreign and troublesome to discipline experts (Manarin \& Abrahamson 2016). A clear strategy is needed to help academics develop these competencies, and it is important to note that even with a clear strategy, the competencies are gained and strengthened only over time. Opportunities should be created for continuous improvement through action and engagement with others doing similar work within and across disciplines (Elmore 2004; Fullan 2006; Osman $\&$ Booth 2015). Lack of support to develop understanding and competencies may lead to non-use of evaluation results (Hojlund 2014) thereby impacting on the possibility of engagement in SoTL. Developing individuals' understanding of SoTL and their skills, as well as providing resources, is important for deep change as opposed to ad hoc and superficial engagement. However, this on its own will not support the change required, but the social context (both at faculty and institutional level) still has to be dealt with.

While the agency of the academic is at the centre of the whole process (making decisions on when to conduct evaluations, interpreting the results, and using them accordingly), it is crucial not to downplay the impact of the particular context in terms of its norms and regulative elements. If the context where social practice is located is contradictory to policy intentions, development of SoTL as a practice is unlikely to be nurtured. It is therefore important for the institution to reflect on its context in order to ensure that it is 
aligned with what needs to be achieved.

More often than not, a discrepancy will exist between the assumed effective way of bringing about change and the contextual reality - hence what happens in faculties (schools/departments) and institution is critical. The culture at both faculty and institutional level often remains unchanged even when new ways of working are introduced. It is then important to reflect on and appreciate the social practice context in terms of how it impacts intended change. Engagement in SoTL as a 'social practice with a context' revolves around a number of interrelated contextual factors (Valters 2015). Trowler (2015) argues that individual agency (both actions and beliefs) interacts with and is influenced by the socio-cultural and structural factors in an institution. Often, we do not think about the context when changes are planned and introduced. To some extent, we overlook the interplay between the acts of the individual agents and the context that shapes and influences what is possible to do and how to do it. The context is characterised not only by ways of doing but also by ways of understanding what people are required to do. This needs to be scrutinised so that it aligns with and supports required change engagement in SoTL.

For example, as a way of supporting and encouraging practices related to SoTL, faculties (or schools and departments) should create a supportive environment, that is, spaces where colleagues can collaborate safely. When academic staff do teaching as an individual project, the process can fail to create support for those academics who are beginning to engage in SoTL. Being deprived of interaction with colleagues has implications for the development of meaningful ways of dealing with problems in teaching contexts. SoTL with its emphasis on communities of learning (Hutchings 2000; Leibowitz 2010) can determine how individual time is used, and often this time is secured for research activities. It is crucial to have access to information on teaching and student learning if academics are to commit to using their time for collaborative work. Making this information accessible guides the work by providing conceptual tools for asking relevant questions. Some ways of working are ingrained in the university context where the norm is for academics to work autonomously. SoTL, with its emphasis on collaboration, implies working against this practice. Collaboration is about peer support; however, this can be realised only when there is leadership support as well. The change is about individuals and the social context where teaching practice is located. 
As part of changing the culture in a social context, it is important to think about 'proactively addressing distractors' (Fullan 2006: 10). This means identifying elements that are counterproductive in supporting envisaged change. Policy requirements should avoid ways of doing that can produce practices that are counterproductive to engagement in SoTL. For instance, the purpose of evaluations is heterogeneous and includes using evaluations for accountability purposes (establish teaching effectiveness). This change the way evaluation results are used and can impact on the safe space that should be created for inquiries in teaching practice and student learning. Evaluations of teaching tend to focus on demonstrating competence in order to support decisions on career progression (probation confirmation and/or promotions). Hojlund (2014: 30) refers to this as the 'legitimisation use' of evaluation results. Not only are evaluations seen as a policing mechanism (Boughey 2001), but participation too would be driven by the need to inform decisions on career progression. Such a stance impacts on efforts to ensure that evaluation feedback on teaching practice feeds into deep reflections and careful decision making on the improvement of teaching practice and student learning. When evaluations are used in this 'instrumental' way, meaningful questions on practice and student learning can be triggered. Of course, the usefulness of the result is dependent on the method used to elicit feedback and the particular academic's capacity to engage in reflections.

What is emphasised as the purpose of evaluations promotes not only a particular way of using the evaluation results but also informs preferred methods of conducting evaluations. The use of surveys to elicit feedback on teaching and learning prevents academics from getting in-depth understanding of practices that support learning and those that need improvement. To deal with this challenge, evaluations need to be reconceptualised, not just how they are used but also their methods and focus - in order to move from teaching effectiveness and teacher performance to student learning (Nygaard \& Belluigi 2011). Teaching and learning need to be understood differently; the process cannot be reduced to a conception of learning informed by a linear input-output model. The methods of conducting evaluations and the use of feedback should be in line with the ideal that evaluations should inform lines of enquiry that feed into engagement in SoTL. The system needs to rethink ways of doing, seeing, and valuing to ensure alignment with engagement in SoTL.

This strengthens the view that an appreciation of the context, its culture, and what is valued is critical when thinking about policy effectiveness 
(Trowler 2015; Valters 2015). Rewarding and valuing SoTL in the same way as other forms of scholarship (Moutlana \& Moloi 2014; Vithal 2016) is important - SoTL is 'serious intellectual work and should be rewarded' (Hutchings \& Shulman 1999: 13). Creative thinking is needed on how SoTL should be rewarded, and not just monetary rewards should be considered. Knowing that SoTL work is appreciated, acknowledged, and valued not just by colleagues but by the institution will promote interest and engagement. Changing the culture of the social context is the most challenging area because of its nebulous nature. According to Elmore (2004: 11), '[c]ultures do not change by mandate; they change by the specific displacement of existing norms, structures, and processes by others'. This does not happen automatically - it requires an institution to reflect honestly on its processes in the light of the intended change. Disruption of normative ways of working and the adoption of practices that nurture the changes expected to support SoTL are critical. Trowler (2015: 164) cautions:

Whenever significant innovations begin they presage new discourses, new types of tools, new agendas and new configurations of power relations and subjectivities. But existing sets of social practices condition response and fundamentally affect the implementation process.

A point to note, institutional culture cannot be overhauled in an instant; it requires a gentle push from different levels until it begins to align with the expected change.

\section{Concluding Remarks}

The discussion in this paper has focused on an institutional policy for the evaluation of teaching, specifically, its connection with encouraging engagement in SoTL. Higher education is replete with activities and demands. Any change that is introduced needs therefore to build on and connect with other institutional activities where possible. When this is done, as in the case of the policy discussed here, it is important to identify the nature of the expected change. Reflection on the thinking underpinning the change can reveal critical areas that need to be revisited and reconceptualised if, in practice, evaluations can meaningfully inform SoTL inquiries. Although policy 
statements highlight opportunities for embedding SoTL in institutional practices such as evaluations, these opportunities may be missed because of failure to develop a strategy to support the change.

This paper has shown, that on the one hand, based on policy directives and goals, questions may be triggered to motivate engagement in SoTL. The way SoTL is viewed in the policy is not far from how SoTL is broadly described in the literature. Evaluations of teaching when conducted appropriately can bring to the fore critical issues of teaching and learning that need attention. On the other hand, the discussion has shown also that some policy directives and institutional context can create an environment for counterproductive practices that can lead to departure from the core intentions of the policy. For example, instead of engaging in the instrumental use of the evaluation results (to inform inquiry), there could be a default to legitimisation use (to justify teaching practice and demonstrate performance for rewards) or non-use. Both the 'legitimisation use' and 'non-use' are a result of what is generally valued in institutions and, to some extent, show a lack of the support needed for change. It cannot summarily be assumed that academic staff will have the capacity to adopt the required ways of working to engage in SoTL without support and an enabling institutional culture. This challenge is directly linked to what Manarin \& Abrahamson (2016: 1) refer to as the 'troublesome knowledge of SoTL' and its associated practices. The competencies required to engage in SoTL, as well as the understanding of its value in transforming higher education teaching and learning, need to be consciously developed and nurtured over time.

This is also true of the required knowledge of evaluations and how feedback can be used to think about and trigger lines of inquiry into teaching in a particular discipline and thus support professional development. There is a need to re-conceptualise evaluations as a practice that supports 'intellectual, professional, and moral' engagement with teaching at individual and institutional level. For evaluation results to inform SoTL, an explicit focus is needed on how students learn in different disciplines and what should be done to improve their success. As part of the process of reframing evaluations, extensive support is required for academics so that they understand the work of SoTL. SoTL is about individual agency, responsibility for conducting evaluations and using the evaluation results to inform engagement in SoTL. This is possible when support is provided to develop capacity so that academics can make appropriate decisions on the areas of teaching and learning they need 
feedback on and the selection of tools to elicit the feedback. The usability of the feedback, especially for SoTL purposes depends on the methods selected for the evaluation and the focus of the evaluation (Saunders 2012).

Reconceptualisation is important for academics and the institution as a whole because of the interplay between agency and the institutional culture - the latter can either support or hinder the achievement of policy goals. Thinking about evaluations differently can help mitigate elements that are counterproductive to SoTL, such as, using evaluations for quality assurance processes. Acknowledgement is needed of the institutional evaluation context with its regulative and normative culture. Appreciation of context will help focus efforts in negotiating and supporting uptake of SoTL as a new practice in an already 'messy' teaching environment in higher education. The context (at both faculty and institutional level) needs to align with the intended change in terms of creating spaces and providing resources to engage in SoTL as well as rewarding and recognising the work done. Rewarding SoTL in ways other than monetary ways can help ensure that motivation is driven by value rather than personal gain.

An action plan for supporting SoTL in institutions is vital for creating opportunities to showcase examples of how it can work successfully. Over time, exposure to the success of SoTL in transforming teaching and learning in different disciplines will reinforce uptake. Besides monetary rewards, exposure to the transformative nature of SoTL will attract engagement eventually leading to a critical mass of scholars engaged in SoTL work.

\section{References}

Booth, S. 2015. On the Scholarship of Pedagogy in Health Sciences. In Booth, S. \& L. Woollacott (eds.): The Scholarship of Teaching and Learning in Higher Education: On its Constitution and Transformative Potential. Stellenbosch: SUNMeDIA.

Booth, S. \& L. Woollacott 2015. Introduction to the Scholarship of Teaching and Learning. In Booth, S. \& L. Woollacott (eds.): The Scholarship of Teaching and Learning in Higher Education: On its Constitution and Transformative Potential. Stellenbosch: SUNMeDIA.

Boshier, R. 2009. Why is the Scholarship of Teaching and Learning Such a Hard Sell? Higher Education Research \& Development 28,1:1-15. 
Boughey, C. 2001. Evaluation as a Means of Assuring Quality in Teaching and Learning: Policing or Development? In Otaala, B. \& F. Opai (eds.): Teach Your Very Best: Selected Proceedings of a Regional Conference for Staff from Tertiary Institutions from SADC Countries. Safari Court and Conference Centre, Windhoek Namibia 1-3 October.

Cameroon, A. 2015. Taking the Scholarly Route in Peer Reviews. In Booth, S. \& L. Woollacott (eds.): The Scholarship of Teaching and Learning in Higher Education: On its Constitution and Transformative Potential. Stellenbosch: SUNMeDIA.

Council on Higher Education. 2015. Content Analysis of the Baseline Institutional Submissions for Phase 1 of the Quality Enhancement Project. Pretoria: Council on Higher Education.

Elmore, R.F. 2004. School Reform from Inside Out: Policy, Practice, and Performance. Cambridge: Harvard University Press.

Fullan, M. 2006. Change Theory: A Force for School Improvement. Centre for Strategic Education Seminar Series Paper no 157. Available at: http:// michaelfullan.ca/wp-content/uploads/2016/06/13396072630.pdf.

(Accessed on 15 May 2017.)

Funnell, S.C. \& P.J. Rogers 2011. Purposeful Program Theory: Effective Use of Theories of Change and Logic Models. New Jersey: John Wiley and Sons.

Hojlund, S. 2014. Evaluation Use in the Organisational Context - Changing Focus to Improve Theory. Evaluation 20,1:26 - 43.

Hutchings, P. 2000. Introduction: Approaching the Scholarship of Teaching and Learning. In Hutchings, P. (ed.): Opening Lines: Approaches to the Scholarship of Teaching and Learning (Menlo Park, CA: The Carnegie Foundation for the Advancement of Teaching. Available at: http:// archive.carnegiefoundation.org/pdfs/elibrary/approaching.pdf. (Accessed on 20 November 2016.)

Hutchings, P. \& L.S. Shulman 1999. The Scholarship of Teaching: New Elaborations, New Developments. Change: The Magazine of Higher Learning 31,5:10-15.

Kreber, C. \& Cranton, P.A. 2000. Exploring the Scholarship of Teaching and Learning. The Journal of Higher Education 71,4:476-495.

Kreber, C. 2007. What's it Really All About? The Scholarship of Teaching and Learning as an Authentic Practice. International Journal for the Scholarship of Teaching and Learning 1,1:1-4. 
Leibowitz, B. 2010. Towards SoTL as Critical Engagement: A perspective from the 'South' 4,2: Article 7. Available at: https://doi.org/10.20429/ ijsotl.2010.040207. (Accessed on 18 November 2016.)

Leibowitz, B. \& V. Bozalek 2015. The Scholarship of Teaching and Learning from a Social Justice Perspective. Teaching in Higher Education 1- 14.

Available at: http://dx.doi.org/10.1080/13562517.2015.1115971.

(Accessed on 18 November 2016.)

Manarin, K. \& E. Abrahamson 2016. Troublesome Knowledge of SoTL. International Journal for the Scholarship of Teaching and Learning 10,2: Article 2. Available at: http://digitalcommons.georgiasouthern.edu/ cgi/viewcontent.cgi?article $=1625 \&$ context=ij-sotl. (Accessed on 18 November 2016.)

Moutlana, I.N. \& K.C. Moloi 2014. Developing the Scholarship of Teaching and Learning at One University of Technology in South Africa. Mediterranean Journal of Social Sciences 5,1:51-59.

Nygaard, C. \& D.Z. Belluigi 2011. A Proposed Methodology for Contextualised Evaluation in Higher Education. Assessment and Evaluation in Higher Education 36,6:657-671.

Osman, R. \& S. Booth 2015. The Scholarship of Teaching and Learning for Educational Transformation. In Booth, S. \& L. Woollacott (eds.): The Scholarship of Teaching and Learning in Higher Education: On its Constitution and Transformative Potential. Stellenbosch: SUNMeDIA.

Pitso, T. 2015. Invitational Pedagogy: An Alternative Practice in Developing Creativity among Undergraduates. In Booth, S. \& L. Woollacott (eds.): The Scholarship of Teaching and Learning in Higher Education: On its Constitution and Transformative Potential. Stellenbosch: SUNMeDIA.

Reckwitz, A. 2002. Toward a Theory of Social Practices: A Development in Culturalist Theorizing. European Journal of Social Theory 5,2:243-263. Saunders, M. 2012. The Use and Usability of Evaluation Outputs: A Social Practice Approach. Evaluation 18,4:421 - 436.

Shulman, L.S. 1999. Taking Learning Seriously. Change: The Magazine of Higher Learning 31,4:10-17.

Stefani, L. 2011. Current Perspectives on SoTL. International Journal for the Scholarship of Teaching and Learning 5,7: Article 2.

Trowler, P. 2015. Change Theory and Changing Practices: Enhancing Student Engagement in Universities in Student Engagement in Europe: Society, Higher Education and Student Governance. Available at: http:// 
eprints.lancs.ac.uk/75524/1/FINAL_Trowler_Student_Engagement_in_ Europe.pdf. (Accessed on 20 November 2016.)

University of the Witwatersrand. Undated. Policy on the Evaluation of Teaching. Available at: http://intranet.wits.ac.za/governance/registrar/Pol icies/Evaluation\%20of\%20Teaching\%20Policy.pdf. (Accessed on 24 January 2016.)

Valters, C. 2015. Theories of Change: Time for a Radical Approach to Learning in Development. Overseas Development Institute Report. The Asian Foundation. Pages 1-20. Available at: https//www.odi.org/sites/odi. org.uk/files/odi-assets/publications-opininon-files/9835.pdf. (Accessed on 20 June 2016.)

Vithal, R. 2016. Growing a Scholarship of Teaching and Learning Institutionally. Studies in Higher Education 1-16. Available at: http://dx.doi.org/10.1080/03075079.2016.1180350. (Accessed on 18 November 2016.)

Rejoice Nsibande Centre for Learning, Teaching and Development Witwatersrand University Rejoice.nsibande@wits.ac.za 